Journal
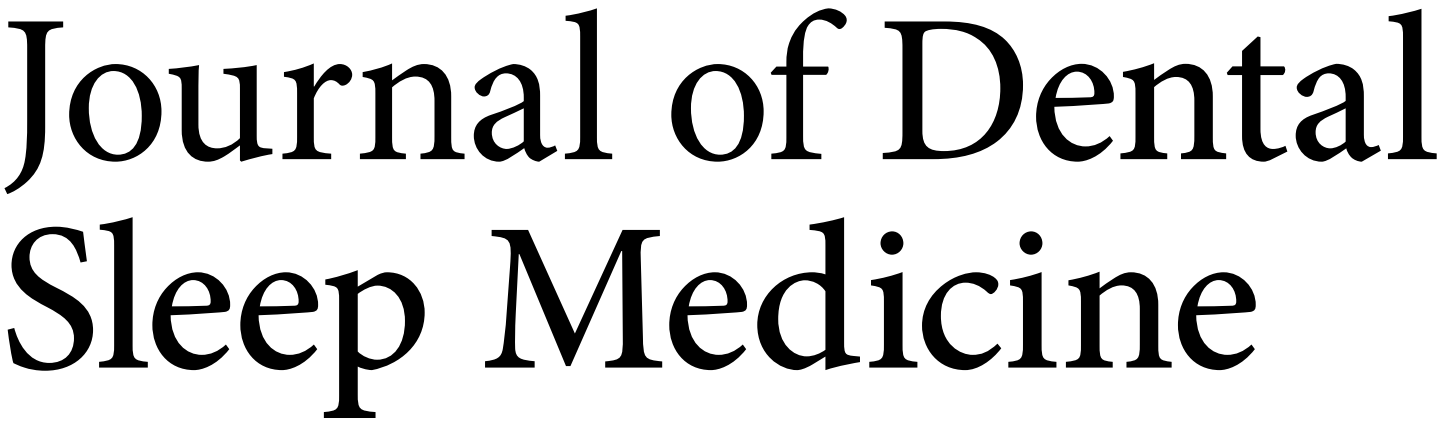

Official Publication of the American Academy of Dental Sleep Medicine | www.jdsm.org

\section{Volume 4, Number 1}

\section{January 10, 2017}

Pages 1-22

\section{In This Issue}

The Prevalence of Pediatric Dentists Who Screen for Obstructive Sleep Apnea Chiang, Reddy, Carrico, Best, Leszczyszyn

A Restorative Technique for the Severe Partial Edentulous and Fully Edentulous CPAP-Resistant Patient Denbar

Airway Evaluation in Response to Hypoglossal Nerve Stimulation: A Case Report Elshebiny, Venkat, Strohl, Strohl, Ponsky, Palomo

Case Report: Retention of a ThermoplasticLined Dental Sleep Appliance Uppgaard 



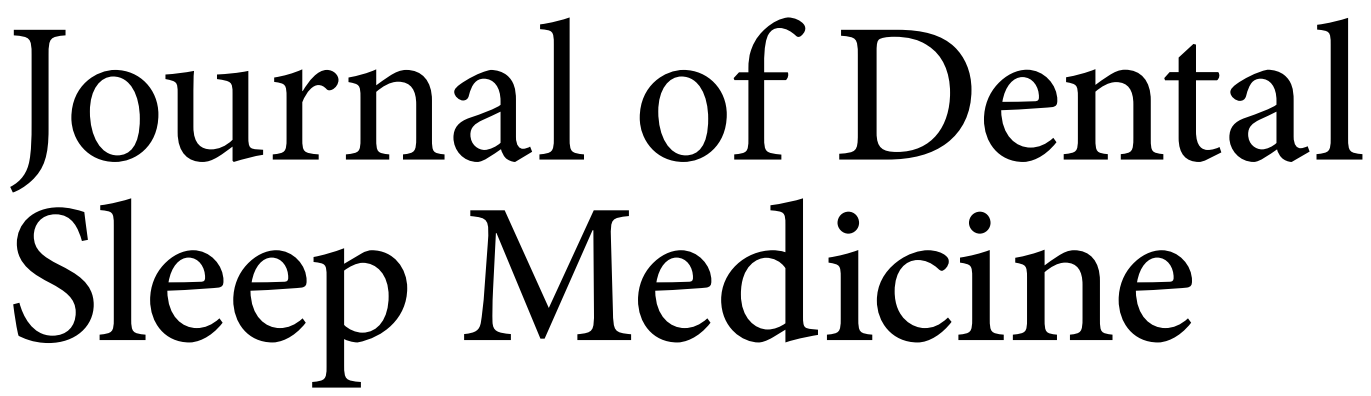

\section{Volume 4, Number 1 | January 10, 2017 | Pages 1-22}

\section{Editor-in-Chief \\ Leslie Dort, DDS \\ Deputy Editor \\ Olivier Vanderveken, MD, PhD}

Associate Editors

Fernanda Almeida, DDS, PhD

Gilles Lavigne, DMD, PhD

Rose Sheats, DMD

\section{Executive Director}

Jerome A. Barrett

\author{
Editorial Board \\ Ghizlane Aarab, DDS, PhD \\ Peter Cistulli, MD, PhD \\ Greg Essick, DDS, PhD \\ Bernard Fleury, MD \\ Nelly Huynh, $\mathrm{PhD}$ \\ Sam Kuna, MD \\ Chris Lettieri, MD \\ Frank Lobbezoo, DDS, PhD \\ Marie Marklund, DDS, PhD \\ Jean-Francois Masse, DMD, MSc \\ Antonio Romero-Garcia, DDS, $\mathrm{PhD}$ \\ Kate Sutherland, BSc(Hons), PhD \\ Satoru Tsuiki, DDS, PhD
}

Journal of Dental Sleep Medicine (JDSM) (Online 2333-9756; Website: www.jdsm.org) is published online quarterly on the $10^{\text {th }}$ of January, April, July and October by the American Academy of Dental Sleep Medicine, 2510 North Frontage Road, Darien, IL 60561-1511, phone (630) 737-9705 and fax (630) 737-9790.

ADVERTISING: Digital advertising is available on www.jdsm.org. Please contact the National Sales Account Executive at advertising@aasmnet.org for complete information.

PERMISSION TO REPRODUCE: Written permission to reproduce, in print or electronically, whole articles or any parts of works, figures or tables published in JDSM must be obtained prior to publication. Permission for republication must be arranged through the Copyright Clearance Center, Inc., 222 Rosewood Drive, Danvers, MA 01923, phone (978) 750-8400 or fax (978) 646-8600 or URL http://www.copyright.com. There are royalty fees associated with such permissions.

REPRINTS: For author reprints contact the AADSM office. For commercial reprint orders contact Cenveo Publisher Services, 4810 Williamsburg Road, \#2, Hurlock, MD 21643 or Reprints2@cadmus.com.
DISCLAIMER: The statements and opinions contained in editorials and articles in this journal are solely those of the authors thereof and not of the American Academy of Dental Sleep Medicine, or of its officers, regents, members or employees. The Editor-in-Chief, the American Academy of Dental Sleep Medicine and its officers, regents, members and employees disclaim all responsibility for any injury to persons or property resulting from any ideas or products referred to in articles contained in this journal.

(C) 2017 American Academy of Dental Sleep Medicine 


\section{EDITORIALS}

3

Two Steps Forward, One Step Back

Leslie C. Dort

\section{ORIGINAL ARTICLES}

5

The Prevalence of Pediatric Dentists Who Screen for Obstructive Sleep Apnea

Harmeet K. Chiang, Nitya Reddy, Caroline Carrico, Al

M. Best, David J. Leszczyszyn

\section{CASE REPORTS}

11

A Restorative Technique for the Severe Partial Edentulous and Fully Edentulous CPAP-Resistant Patient

Martin A. Denbar

15

Airway Evaluation in Response to Hypoglossal Nerve Stimulation: A Case Report

Tarek Elshebiny, Divya Venkat, Madeleine Strohl, Kingman Strohl, Diana Ponsky, Juan Martin Palomo

19

Case Report: Retention of a Thermoplastic-Lined Dental Sleep Appliance

Rachel M. Uppgaard

\section{LETTERS TO THE EDITOR}

21

Monobloc or Adjustable MAD?

Hendrik J. Remmelink 


\title{
Two Steps Forward, One Step Back
}

\author{
Leslie C. Dort, DDS, Diplomate, ABDSM, Editor-in-Chief Journal of Dental Sleep Medicine
}

Calgary, Alberta, Canada

The scene: a dental sleep medicine professional is preparing a presentation on the multiple negative consequences of insufficient sleep; she takes a break and turns on the television. Her face registers shock and dismay while watching an advertisement for a Microsoft tablet.

Why? Watch and draw your own conclusion: https://www. youtube.com/watch?v=Yjs2uiKPo2c.

There are considerable efforts being made to inform the public as to the benefits of sufficient sleep and the likely consequences of inadequate sleep. The National Health Sleep Awareness Project (NHSAP) is one example of these efforts. The NHSAP is a multidisciplinary, multiyear project of the Centers for Disease Control and Prevention awarded to the American Academy of Sleep Medicine. The primary aim of the NHSAP is to reduce the burden of poor sleep and sleep disorders in the population, because there is growing evidence of the negative consequences of inadequate sleep. ${ }^{1}$

The associations that inadequate sleep has with poor health and diminished well-being include ${ }^{2}$ :

- Physical health: particularly cardiovascular disease

- Mental health: including symptoms and diagnosis of depression

- Neurocognitive health: including diminished human performance and executive functioning

- Safety: notably increased motor vehicle accident rates in both adults and teenagers

It is disappointing to see a prominent technology company portray a leader in a very intriguing field as someone whose strength or "superpower" is to "never sleep." The obvious interpretation is that those with interesting jobs must work all the time and sacrifice sleep time. The superhero content in this ad will likely attract the attention of adults and teenagers alike.

Nationwide surveys such as the Youth Risk Behavior Surveillance System report that inadequate sleep is common not only in adults but in teenagers as well. Early school start times and ever-increasing time spent on "devices" are two factors that can lead to short sleep in this group. ${ }^{3}$

It is disappointing when industry leaders with deep pockets do not use their influence to promote healthy lifestyles. Perpetuating the belief that "success" follows one who works all the time using technology and "never sleeps" is not a positive influence on our health and safety. Let us challenge industry to use its influence to promote health and healthy sleep.

\section{CITATION}

Dort LC. Two steps forward, one step back? Journal of Dental Sleep Medicine. 2017;4(1):3.

\section{REFERENCES}

1. National Healthy Sleep Awareness Project. Centers for Disease Control and Prevention Web site. http://www.cdc.gov/sleep/projects_partners. html. Updated December 9, 2014. Accessed December 8, 2016.

2. Watson NF, Badr MS, Belenky G, et al. Joint consensus statement of the American Academy of Sleep Medicine and Sleep Research Society on the recommended amount of sleep for a healthy adult: methodology and discussion. J Clin Sleep Med. 2015;11(8):931-952.

3. Morgenthaler TI, Hashmi S, Croft JB, Dort L, Heald JL, Mullington J. High school start times and the impact on high school students: what we know, and what we hope to learn. JClin Sleep Med. 2016;12(12):16811689.

\section{SUBMISSION \& CORRESPONDENCE INFORMATION}

Submitted for publication December, 2016

Accepted for publication December, 2016

Address correspondence to: Leslie C. Dort, DDS, 1016-68th Ave SW,

Suite 150, Calgary, AB T2V 4J2, Canada; Tel: (403) 202-4905; Fax:

(403)202-0266; Email: lcdort@gmail.com

\section{DISCLOSURE STATEMENT}

Dr. Dort is Editor-in-Chief of the Journal of Dental Sleep Medicine. 



\title{
The Prevalence of Pediatric Dentists Who Screen for Obstructive Sleep Apnea
}

Harmeet K. Chiang, DDS, MS'; Nitya Reddy, MS'; Caroline Carrico, PhD'; Al M. Best, PhD'; David J. Leszczyszyn, MD, PhD²

${ }^{1}$ School of Dentistry, Virginia Commonwealth University, Richmond, VA; ${ }^{2}$ School of Medicine, Virginia Commonwealth University, Richmond, VA

\begin{abstract}
STUdy ОвJеCтives: To estimate the prevalence of screening for OSA by pediatric dentists associated with the American Academy of Pediatric Dentistry (AAPD).

MEтHODS: Members of the AAPD were solicited to participate in an online survey. Associations with demographic characteristics were tested using logistic regression.

Results: Overall, only $70 \%$ of pediatric dentists do some form of screening for OSA. Compared to pediatric dentists in practice more than $30 \mathrm{y}$, those in practice less than $5 \mathrm{y}$ are significantly more likely to report screening for OSA $(82 \% \mathrm{versus} 60 \%$, $\mathrm{p}=0.0389)$. Compared to pediatric dentists located in the northeast, those practicing in the western states are significantly more likely to report screening for OSA ( $82 \%$ versus $60 \%, \mathrm{p}=0.0104)$. Approximately $72 \%$ of pediatric dentists report some lack of confidence regarding their capability for OSA screening.
\end{abstract}

Conclusions: These data demonstrates the need for pediatric dentists to become more aware of OSA screening methods, and the screening tools need to be improved so that they may be applied more accurately and confidently.

KEYWORDS: obstructive sleep apnea, pediatric dentists, screening

Citation: Chiang HK, Reddy N, Carrico C, Best AM, Leszczyszyn DJ. The prevalence of pediatric dentists who screen for obstructive sleep apnea. Journal of Dental Sleep Medicine. 2017;4(1):5-10.

\section{INTRODUCTION}

Pediatric obstructive sleep apnea (OSA) is a disorder characterized by repeated episodes of upper airway obstruction during sleep lasting for more than two usual respiratory cycles. This results in apneas (breathing pauses, shallowing breathing episodes, and respiratory effort-related arousals) all of which lead to interruptions in sleep. ${ }^{1}$ OSA most commonly affects children between the ages of 2 to $7 \mathrm{y}$, an especially critical time for growth and development. ${ }^{1,2}$ The consequences of untreated OSA in children are myriad, with some of the more common including failure to thrive, enuresis, attention-deficit disorder, behavioral problems, daytime sleepiness, and poor academic performance. ${ }^{2}$ Additionally, OSA places a burden on the cardiovascular system due to "acute increases in blood pressure and arrhythmias associated with apneas and intermittent hypoxia," which can have harmful and lasting effects as children grow. ${ }^{1}$

The importance of screening children for OSA cannot be stressed enough. It has been estimated that $82 \%$ to $93 \%$ of adults with OSA remain undiagnosed. ${ }^{3}$ Likewise, OSA has recently been recognized as one of the most common and underdiagnosed chronic childhood diseases. ${ }^{4}$ The alarming increase in childhood obesity over the past few decades has been associated with an increase in the prevalence of OSA from a stable $1 \%$ to $4 \%$ to as high as $19 \%$ to $61 \%$, increasing the importance of OSA screening in children by health care providers. ${ }^{5}$

Pediatric dentists can play an important role in the screening of OSA. Because adenotonsillar hypertrophy is the most common etiology, the simple recognition and documentation of the size of the tonsils during a head and neck examination can lead to a referral to the patient's primary care physician or a sleep specialist. ${ }^{1,2}$ Physicians may not always recognize childhood OSA and there is evidence to support a delay of up to 23 mo between identification of a pediatric patient with large tonsils and referral of that patient to a sleep clinic or laboratory. As stated by Padmanabhan et al., because pediatric dentists are more likely to identify adenotonsillar hypertrophy than physicians, pediatric dentists could be the gatekeepers in screening children for OSA. ${ }^{1}$ Although there is ample research on treatments and screening methods, there is no research on the prevalence of screening among pediatric dentists.

The primary aim of this study is to determine the prevalence of pediatric dentists who screen for OSA and to identify what methods they use in their screening process.

\section{METHODS}

\section{Patients}

This study was approved as exempt by an Institutional Review Board (IRB: \#HM200003462). An email invitation was sent by a third-year dental student as a part of the research project in December 2015 to approximately 5,500 pediatric dentists who were members of the American Academy of Pediatric Dentistry (AAPD) asking them to participate in a survey using the REDcap (Research Electronic Data Capture) survey software. The email invitation asked members to participate if they had practiced dentistry within the past year and that participation would be greatly appreciated, but is completely voluntary and will remain anonymous. No compensation was 

Figure 1-Obstructive sleep apnea (OSA) screening
modalities.

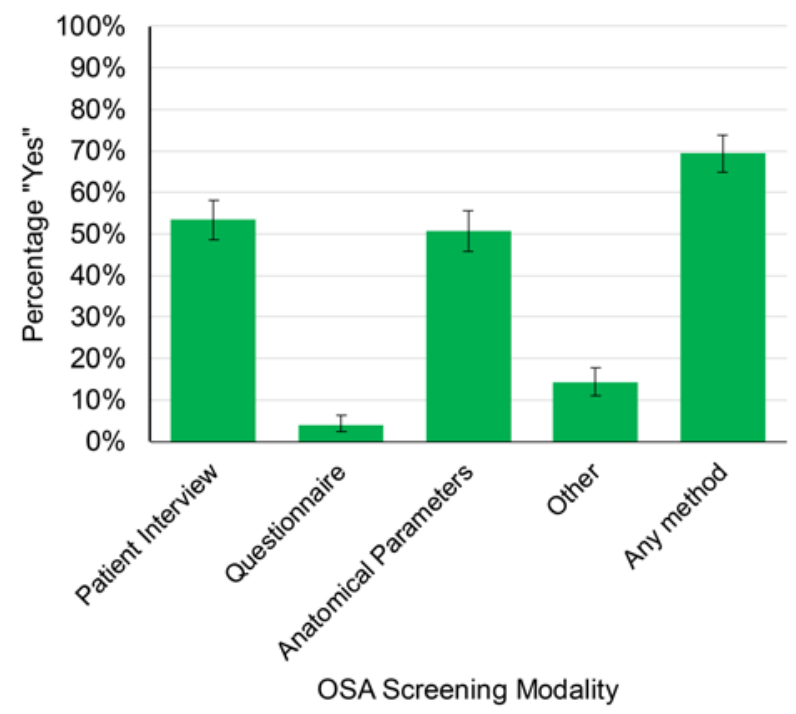

The percentage "Do you screen for OSA = Yes" and 95\% confidence intervals were estimated using logistic regression. The "other" modalities are any of the four listed in Table 2. "Any method" is the use of any of the three primary modalities or any of the four other modalities.

provided for participation. A respondent was required to be a practicing pediatric dentist to be eligible for inclusion in the analyses.

\section{Questionnaire}

The questionnaire consisted of a demographic section (years in practice, dental school, practice specialty, practice setting, practice location) followed by a series of questions regarding screening methods, preferences, referrals, and treatment modalities. Three primary screening modalities were considered (medical history, sleep questionnaire, and anatomic parameters) as well as three additional modalities (cone beam computed tomography, home sleep test, two-dimensional lateral cephalogram) and other modalities. The preferred modality was recorded, as was the percentage of patients routinely screened and the level of confidence in screening. Referral behavior and treatment services were recorded in the final portion of the questionnaire.

The primary outcome variable was whether any screening for OSA was reported. A positive answer or "Yes" was accepted if any of the primary or additional modalities were reported. In order to identify any geographic associations the five districts of the AAPD were used. ${ }^{6}$ The district of the respondent's dental school was used, as was the district of the dental practice location.

\section{Statistical Methods}

Frequency and proportions were calculated for the responses to items on the questionnaire, and the results are reported using 95\% confidence intervals. Additionally, logistic regression was used to determine if the demographic factors were associated with screening for OSA. Factors were first screened one at a time and then those factors remaining significant in a multivariable logistic regression using a significance level of 0.05 were reported. SAS software (SAS v9.4, EG v6.1, and JMP Pro 12.2, SAS Institute Inc., Cary NC) was used for all analyses.

\section{RESULTS}

A total of 455 dentists responded to the survey, an $8 \%$ response rate, but 7 were excluded because they were practicing as general dentists or in specialties other than pediatric dentistry. Although $8 \%$ is a low response rate based on the reported demographics of the 448 pediatric dentists and the large sample size, we expect this sample to be representative of the population of pediatric dentists. Table 1 shows the demographic characteristics and indicates a large number of pediatric dentists in a range of locations with a variety of experience. We grouped practice location into North Central, North East, South East, South West, and West. All groups were represented evenly. There were $83 \%$ who reported practicing in private practice whereas $9 \%$ practiced in academia. There was an even distribution of dentists in practice ranging from less than $5 \mathrm{y}$ to more than $30 \mathrm{y}$.

When asked whether they screen for OSA, more than $70 \%$ of pediatric dentists studied reported that they did so using one of the specified modalities (see Table 2 and Figure 1). More than one-half screen using a patient interview (55\%) or by identifying anatomical parameters (52\%) and fewer than $5 \%$ use a sleep questionnaire. In those who use a patient interview, 53\% inquire about snoring or pauses in breathing and $47 \%$ observe whether mouth breathing occurs. Additionally, 22\% inquire about excessive daytime fatigue and $20 \%$ recognize high body mass index as a risk factor. Fewer than 9\% report observing other aspects during the patient interview. Of those who identify anatomical features, $51 \%$ report observing the position and size of tonsils and adenoids. An additional $36 \%$ observe the mandible position and size. Among the few that use a questionnaire, the variety of choices-including self-developed forms-indicates no consensus on this modality.

The results show that just fewer than $30 \%$ of pediatric dentists do not routinely screen their patients for OSA. This is a significant portion of the pediatric population. More importantly, even among those who do some screening only $40 \%$ report screening all of their patients; on average, only $66 \%$ of patients are screened. Overall when asked about their confidence in screening for OSA, $72 \%$ of pediatric dentists report that they were "uncomfortable" (i.e., 1 or 2 on the 5 -point scale, Figure 2). Although it is not surprising that almost all of those who do no OSA screening are not entirely confident, $60 \%$ of those who use some form of screening still report some level of discomfort.

In order to determine if there is any demographic pattern to the prevalence of OSA screening, the chi-square test was used to test for an association with all of the factors described in Table 1. There was no evidence for an association ( $p>0.34)$ except for years of practice $(\mathrm{p}=0.0235)$ and practice location $(\mathrm{p}=0.0324)$. A multivariable logistic regression confirmed 
Table 1-Demographic characteristics of pediatric dentists $(n=448)$.

\begin{tabular}{|c|c|c|}
\hline Demographic Factor & $\mathbf{n}$ & Percent \\
\hline \multicolumn{3}{|c|}{ How many years have you practiced dentistry? } \\
\hline Fewer than 5 & 86 & 19.3 \\
\hline $5-10$ & 98 & 22.0 \\
\hline $11-20$ & 111 & 24.9 \\
\hline $21-30$ & 78 & 17.5 \\
\hline More than 30 & 72 & 16.2 \\
\hline \multicolumn{3}{|c|}{ In which setting are you primarily involved with dentistry? } \\
\hline Private Practice & 373 & 83.3 \\
\hline Academia & 39 & 8.7 \\
\hline Public Health & 13 & 2.9 \\
\hline Hospital & 15 & 3.4 \\
\hline Military & 6 & 1.3 \\
\hline Insurance & 1 & 0.2 \\
\hline Other & 1 & 0.2 \\
\hline \multicolumn{3}{|c|}{ How would you describe your practice setting? } \\
\hline Metropolitan (more than 50,000) & 130 & 30.2 \\
\hline Large City $(50,000-50,000)$ & 158 & 36.7 \\
\hline Small City $(20,000-50,000)$ & 113 & 26.3 \\
\hline Rural (less than 20,000 ) & 29 & 6.7 \\
\hline \multicolumn{3}{|l|}{ Practice location } \\
\hline $\mathrm{NC}$ & 61 & 14.8 \\
\hline NE & 90 & 21.8 \\
\hline SE & 80 & 19.4 \\
\hline SW & 88 & 21.4 \\
\hline W & 93 & 22.6 \\
\hline \multicolumn{3}{|l|}{ Dental school location (DDS/DMD) } \\
\hline $\mathrm{NC}$ & 67 & 18.36 \\
\hline NE & 102 & 27.95 \\
\hline SE & 83 & 22.74 \\
\hline SW & 49 & 13.42 \\
\hline W & 64 & 17.53 \\
\hline
\end{tabular}

Not every respondent replied to every question. The percentages were based on those responding to the question. Practice and dental school location identified by collapsing the state into a grouping by the AAPD Districts. NC $=$ North Central, NE $=$ North East, $S E=$ South East, $S W=$ South West, $\mathrm{W}=$ West.

that there was a significant association between whether or not a provider reported screening for OSA and years of practice $(\mathrm{p}=0.0342)$ and practice location $(\mathrm{p}=0.0247$, Table 3 and Figure 3). Tukey post hoc test was used to identify the group differences and, compared to pediatric dentists in practice more than $30 \mathrm{y}$, those in practice fewer than $5 \mathrm{y}$ are significantly more likely to report screening for OSA ( $82 \%$ versus $60 \%$, relative risk $=1.36, p=0.0389$ ). There were no other differences between the years in practice groups. In addition, as compared to pediatric dentists located in the northeast, those practicing in the western states are significantly more likely to report screening for OSA ( $82 \%$ versus $60 \%$, relative risk $=1.38, p=0.0104)$. There were no other significant differences between the practice locations.

Approximately $90 \%$ of pediatric dentists who suspect patients have OSA refer them to physicians for further evaluation. Only $7 \%$ of pediatric dentists provide treatment for their patients with OSA. Of the $7 \%, 76 \%$ focus on providing treatment for both the maxilla and mandible, with the most common appliance being the rapid palatal expander.
Figure 2-Self-reported confidence in screening for obstructive sleep apnea (OSA).

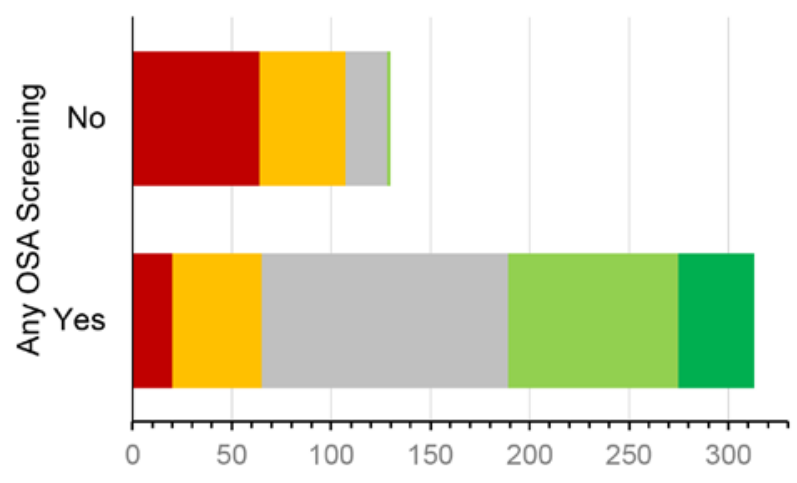

- 1 (uncomfortable) $₫ 2 \backsim 3 \backsim 4 \backsim 5$ (very confident)

In the two groups of "Do you screen for any OSA?", the numbers of pediatric dentists are shown broken down by "Please characterize your confidence in screening for OSA." 
Table 2-Prevalence of screening for obstructive sleep apnea.

\begin{tabular}{|c|c|c|}
\hline Do you screen for OSA ... & $n$ & Percen \\
\hline \multicolumn{3}{|l|}{ Primary screening modalities } \\
\hline \multicolumn{3}{|c|}{ While obtaining medical history through a patient interview? } \\
\hline No & 204 & 45.5 \\
\hline Yes & 244 & 54.5 \\
\hline \multicolumn{3}{|c|}{ Through a written sleep questionnaire? } \\
\hline No & 424 & 95.3 \\
\hline Yes & 21 & 4.7 \\
\hline \multicolumn{3}{|c|}{ By specifically identifying anatomic parameters? } \\
\hline No & 217 & 48.6 \\
\hline Yes & 230 & 51.5 \\
\hline \multicolumn{3}{|l|}{ Other screening modalities } \\
\hline \multicolumn{3}{|c|}{ Using cone beam computed tomography } \\
\hline No & 443 & 98.9 \\
\hline Yes & 5 & 1.1 \\
\hline \multicolumn{3}{|l|}{ Using a home sleep test } \\
\hline No & 439 & 98.0 \\
\hline Yes & 9 & 2.0 \\
\hline \multicolumn{3}{|c|}{ Using 2D lateral cephalogram } \\
\hline No & 423 & 94.4 \\
\hline Yes & 25 & 5.6 \\
\hline \multicolumn{3}{|l|}{ Using other methods } \\
\hline No & 408 & 91.1 \\
\hline Yes & 40 & 8.9 \\
\hline \multicolumn{3}{|l|}{ Any OSA screening } \\
\hline No & 132 & 29.5 \\
\hline Yes & 316 & 70.5 \\
\hline
\end{tabular}

Not every respondent replied to every question. The percentages were based on those responding to the question. $2 \mathrm{D}=$ two dimensional; OSA = obstructive sleep apnea.

\begin{tabular}{|c|c|c|}
\hline Demographics & Percent & $95 \% \mathrm{Cl}$ \\
\hline \multicolumn{3}{|c|}{ How many years have you practiced dentistry? } \\
\hline Fewer than 5 & $81.5^{\mathrm{a}}$ & 71.3 to 88.7 \\
\hline $5-10$ & $66.2^{a, b}$ & 55.5 to 75.5 \\
\hline $11-20$ & $65.3^{a, b}$ & 55.3 to 74.2 \\
\hline $21-30$ & $76.0^{\mathrm{a}, \mathrm{b}}$ & 64.7 to 84.6 \\
\hline More than 30 & $60.1^{\mathrm{b}}$ & 48.0 to 71.0 \\
\hline \multicolumn{3}{|l|}{ Practice Location } \\
\hline NC & $68.3^{a, b}$ & 55.3 to 78.9 \\
\hline NE & $59.6^{a}$ & 48.9 to 69.4 \\
\hline SE & $66.7^{\mathrm{a}, \mathrm{b}}$ & 55.5 to 76.3 \\
\hline SW & $72.6^{\mathrm{a}, \mathrm{b}}$ & 62.1 to 81.1 \\
\hline W & $82.1^{\mathrm{b}}$ & 73.0 to 88.7 \\
\hline
\end{tabular}

Percentage using any screening modality (and confidence intervals) estimated using logistic regression. Significant differences identified by Tukey's multiple comparison procedure. Estimates not sharing the same superscript were significantly different $($ alpha $=0.05)$. $\mathrm{Cl}=\mathrm{confidence}$ interval; NC = North Central, NE = North East, SE = South East, SW = South West, W = West.

\section{DISCUSSION}

There are three main screening methods dentists can use to screen for OSA. First, a dentist could perform a physical examination of the hard and soft palate, specifically focusing on the adenotonsillar tissue. Second, a dentist could use a questionnaire asking the patient or patient's parent/guardian about their body mass index, snoring, daytime alertness, etc. A questionnaire could be a concise and easy-to-use tool to screen for OSA but currently there is no standardized survey for practitioners to use. ${ }^{7}$ A metaanalysis showed that only one survey, the Pediatric Sleep Questionnaire, ${ }^{8,9}$ had the diagnostic accuracy to be used as screening method for OSA in pediatric patients. Though it cannot replace the gold standard of a full polysomnography, it could be a quick 
Figure 3-Self-reported percentage screening for obstructive sleep apnea (OSA) by years in practice and practice location.

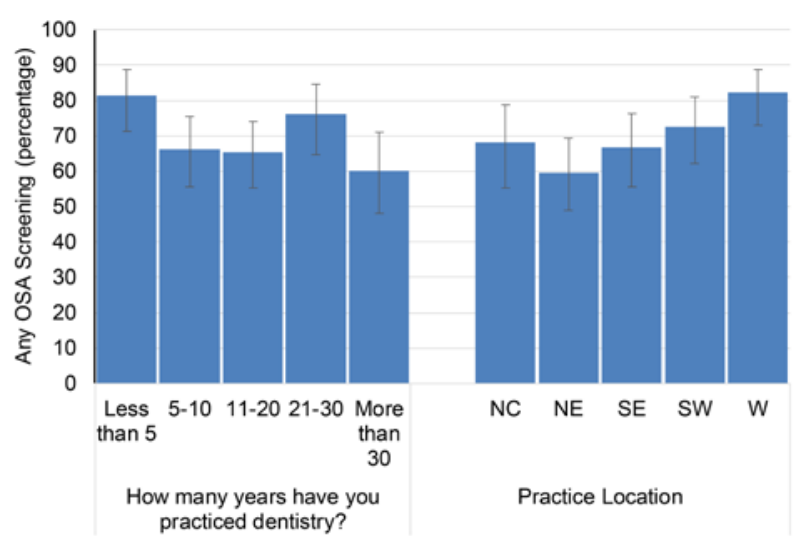

The percentage of "Do you screen for any OSA?" were estimated from logistic regression. Compared to pediatric dentists in practice more than $30 \mathrm{y}$, those in practice fewer than $5 \mathrm{y}$ are significantly more likely to report screening for OSA ( $82 \%$ versus $60 \%$, $p=0.0389$ ), and, as compared to pediatric dentists located in the northeast, those practicing in the western states are significantly more likely to report screening for OSA ( $82 \%$ versus $60 \%$,

$p=0.0104)$. NC = North Central; NE = North East; SE = South East; SW = South West; $\mathrm{W}=$ West.

and efficient way to incorporate screening of OSA into routine patient care. Last, pediatric dentists could interview the patient, which may provide more information because a one-on-one interview is by nature more personal and intimate.

Some may argue that OSA is outside the scope of care of a dental provider and their role in this area is not clearly defined. However, the primary cause of OSA in children is enlargement of adenotonsillar tissue, which is clearly visible during the head and neck examination. ${ }^{1}$ Dentists receive extensive instruction on head and neck anatomy and physiology and specialize in this area to a much greater degree than a pediatrician. They are specifically trained to perform head and neck examinations; therefore, OSA screenings could easily be incorporated into the intraoral examination.

According to the National Institute of Dental and Craniofacial Research, the prevalence of oral cancer is $0.0044 \%$ in children age $0-19 \mathrm{y} \cdot{ }^{10}$ In contrast, OSA affects $1 \%$ to $10 \%$ of children in the United States and has significant sequelae when left untreated. ${ }^{2}$ Oral cancer screening is part of routine care and the dentist is considered negligent if this screening is not performed during every patient visit. However, it is unknown how many or if any pediatric dentists screen for OSA, even though the prevalence of OSA is significantly higher than that of oral cancer.

Smoking and tobacco cessation counseling was once thought to be beyond the scope of care of a dentist but it has been shown to be effective in practice and is being incorporated into dental schools' curriculum. ${ }^{11}$ Smoking directly affects the health of teeth and gingiva and can have significant effects on surgery, healing, and oral cancer risk. As more was learned about these detrimental effects, health care providers began to counsel their patients and explain to them how tobacco can affect the oral cavity. Similarly, as more is learned about the negative consequences of untreated OSA and how the condition remains undiagnosed in many children, the importance of screening becomes paramount. Our results show that more recent graduates (practicing fewer than 5 y) are 2.5 times more likely to screen for OSA than those who have been practicing for more than $30 \mathrm{y}$, which indicates that OSA is slowly starting to become included in dental school and residency program curricula.

Health care currently is evolving into a personal approach for patients, which is only possible through an interdisciplinary and interprofessional collaboration of dentists and physicians. OSA is an area that pediatric dentists could work in conjunction with other health care providers, such as pediatricians or nurse practitioners, to better serve their patients.

In conclusion, fewer than one-third of pediatric dentists screen $100 \%$ of their patients for OSA and an additionally $31 \%$ do not screen at all, which is a significant portion of the pediatric population. Furthermore, the majority of dentists report a lack of confidence in screening for OSA and 93\% do not provide treatment for OSA. This lack of comfort and confidence in recognizing and diagnosing OSA may be attributed to the fact that dental students receive fewer than $4 \mathrm{~h}$ of overall education in sleep disorders, let alone in OSA itself. ${ }^{12}$ Together our findings and the state of undergraduate dental sleep education demonstrate the need for a standardized approach for screening and for pediatric dentists to become more aware and better trained to help accurately and confidently screen for OSA.

\section{REFERENCES}

1. Padmanabhan V, Kavitha PR, Hegde AM. Sleep disordered breathing in children--a review and the role of a pediatric dentist. J Clin Pediatr Dent. 2010;35(1):15-21.

2. Chan J, Edman JC, Koltai PJ. Obstructive sleep apnea in children. Am Fam Physician. 2004;69(5):1147-1154.

3. Peppard PE, Young T, Barnet JH, Palta M, Hagen EW, Hla KM. Increased prevalence of sleep-disordered breathing in adults. Am J Epidemiol. 2013;177(9):1006-1014.

4. Church GD. The role of polysomnography in diagnosing and treating obstructive sleep apnea in pediatric patients. Curr Probl Pediatr Adolesc Health Care. 2012;42(1):2-25.

5. Andersen IG, Holm JC, Homoe P. Obstructive sleep apnea in obese children and adolescents, treatment methods and outcome of treatment - a systematic review. Int J Pediatr Otorhinolaryngol. 2016;87:190-197.

6. District and state pediatric dentistry chapters. American Academy of Pediatric Dentistry Web site. http://www.aapd.org/about/affiliated/. Accessed November 23, 2016.

7. Chiang HK, Cronly JK, Best AM, Brickhouse TH, Leszczyszyn DJ. Development of a simplified pediatric obstructive sleep apnea (OSA) screening tool. Journal of Dental Sleep Medicine 2015;2(4):163-173.

8. Chervin RD, Hedger K, Dillon JE, Pituch KJ. Pediatric sleep questionnaire (PSQ): validity and reliability of scales for sleepdisordered breathing, snoring, sleepiness, and behavioral problems. Sleep Med. 2000;1(1):21-32.

9. De Luca Canto G, Singh V, Major MP, et al. Diagnostic capability of questionnaires and clinical examinations to assess sleep-disordered breathing in children: a systematic review and meta-analysis. J Am Dent Assoc. 2014;145(2):165-178.

10. Oral cancer prevalence (total number of cases) by age. National Institute of Dental and Craniofacial Research Web site. http:// www.nidcr.nih.gov/DataStatistics/FindDataByTopic/OralCancer/ OralCancerPrevalence.htm. Updated May 28, 2014. Accessed November 23, 2016. 
11. Stevens VJ, Severson H, Lichtenstein E, Little SJ, Leben J. Making the most of a teachable moment: a smokeless-tobacco cessation intervention in the dental office. Am J Public Health. 1995;85(2):231-235.

12. Simmons MS, Pullinger A. Education in sleep disorders in US dental schools DDS programs. Sleep Breath. 2012;16(2):383-392.

\section{SUBMISSION \& CORRESPONDENCE INFORMATION}

Submitted for publication September, 2016

Submitted in final revised form November, 2016

Accepted for publication November, 2016

Address correspondence to: Harmeet K. Chiang, PO Box 566, School of

Dentistry, Virginia Commonwealth University, Richmond, VA 23298-

0566; Email: hkchiang@vcu.edu

\section{DISCLOSURE STATEMENT}

Study data were collected and managed using REDCap (Research Electronic Data Capture) electronic data capture tools hosted at Virginia Commonwealth University (Harris et al. Research electronic data capture (REDCap) - a metadata-driven methodology and workflow process for providing translational research informatics support. J Biomed Inform. 2009;42(2):377-381.). REDCap is a secure, web-based application designed to support data capture for research studies. This was not an industry supported study. The authors have indicated no financial conflicts of interest. 


\title{
A Restorative Technique for the Severe Partial Edentulous and Fully Edentulous CPAP-Resistant Patient
}

\author{
Martin A. Denbar, DDS, Diplomate, ABDSM
}

Texas A\&M School of Medicine

\begin{abstract}
A case report detailing the use of an oral appliance for severely partially edentulous and fully edentulous patents without the need for implants.

KEYWORDS: balanced occlusion, fully edentulous, partially edentulous, posterior stops

Citation: Denbar MA. A restorative technique for the severe partial edentulous and fully edentulous CPAP resistant patient. Journal of Dental Sleep Medicine. 2017;4(1):11-13.
\end{abstract}

\section{INTRODUCTION}

One of the challenges faced by the dental sleep medicine clinician is the resistance to continuous positive airway pressure (CPAP) in a patient who is partially or fully edentulous and possibly with limited finances. Dental implants are an excellent option if the patient can afford them, but unfortunately there are many patients who cannot. This report presents two cases, one in which the patient has only three natural lower teeth and a partially edentulous maxillary arch (Figure 1) and the other case in which the patient is fully edentulous (Figure 2). For both of these cases, existing technology was used that allows the oral appliance to be treated as a regular full or partial denture for prosthetic purposes while still maintaining the original triple laminate liner for any remaining dentition.

One of the major issues with fewer teeth is the lack of retention of and stability for an oral appliance. The SR Ivocap Injection System (Ivoclar Vivadent Inc., Amherst, NY) was used to produce an appliance base that could be modified with chairside or laboratory relines or rebases for stability purposes. This injection system controls the heat/pressure polymerization and regulates the exact amount of material flowing into the flask to compensate for any acrylic shrinkage, allowing for a highly accurate fit with minimal appliance adjustment when seated. As the ridge anatomy changes with age and use, the appliance's inner lining can be easily readapted with chairside relines, soft or hard, for the partially edentulous patient and with chairside or laboratory rebase and relines for the fully edentulous individual.

\section{CASE \#1}

A 58-y-old female patient with a diagnosis of moderate obstructive sleep apnea (OSA) was referred by her physician of record to my office for oral appliance therapy in May 2016. The polysomnogram (PSG) from July 27, 2014 showed an apneahypopnea index (AHI) of 11.5 events/h, a respiratory disturbance index of 28.1 events $/ \mathrm{h}$, and a nadir of $81 \%$. The patient's Epworth Sleepiness Scale ${ }^{1}$ score was 13 and Fatigue Severity
Scale (FSS) ${ }^{2}$ was 63. Her prescribed CPAP had been $9 \mathrm{~cm} \mathrm{H}_{2} \mathrm{O}$ but she was unable to successfully use her positive airway pressure (PAP) machine because it interrupted her sleep, the head gear was uncomfortable, her movements were restricted, and the machine was cumbersome. The patient's sleep schedule was highly irregular with multiple 1 - to 3 -h sleep periods during a 24 -h cycle. She was being treated for attention deficit disorder/attention deficit hypertensive disorder, gastrointestinal reflux disease, hypersomnolence, high blood pressure, chronic obstructive pulmonary disease, fibromyalgia, and bipolar manic depression. The patient's current medications are Amitriptyline, Fluticasone furoate/vilanterol, Levalbuterol, Lidocaine patch, Lisinopril, Mirtazapine, and Montelukast. She continues to smoke one-half pack of cigarettes a day. Her existing teeth were $\# 5,6,7,8,9,10,11,12,21,22$, and 27 . The patient had class 2 periodontal disease with normal mobility of all teeth.

A triple laminate appliance design was chosen for therapy with the metal hardware transferred to processed denture material. As seen on the models, the appliance used different base material in the different divided areas. The areas adjacent to the teeth used a triple laminate material and beyond this area a standard clear denture material was used (Figure 3). The injection system was used to create a standard denture base. The heat needed for the denture material processing did not distort or degrade the triple laminate. Now, the main tissue supporting areas can be relined chairside as needed to maintain the appliance's stability.

The initial bite was taken from the maxillary and mandibular cuspid end-on position. This bite position is a reproducible starting titration point for this patient. Normally an incisal end-on bite position is utilized as a reproducible starting point rather than the George gauge. A maxillary and mandibular impression was taken using a two-part, chemically compatible, irreversible hydrocolloid impression material.

At the delivery appointment both upper and lower appliances were seated with posterior stops placed, creating a three-point balanced occlusion. In creating the posterior stops, more occlusal pressure is placed on the two posterior 


\section{Figure 1}

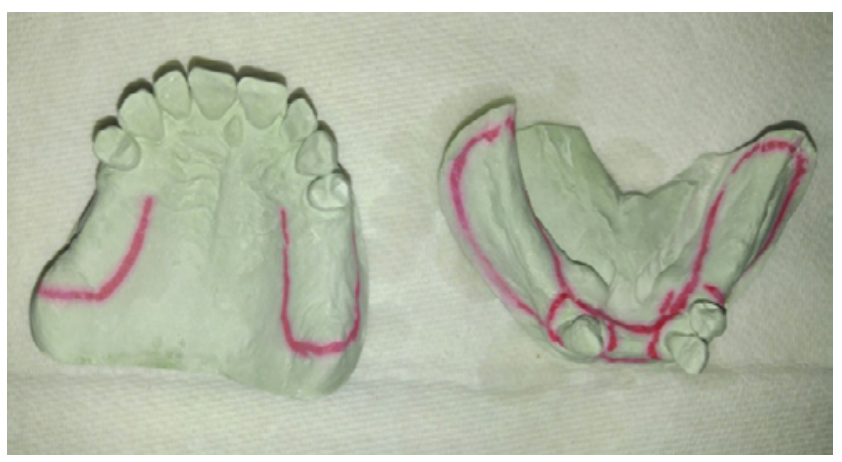

Areas marked in red not immediately next to the teeth are where the normal clear denture material is located. Areas in red approximating the teeth have triple laminate material.

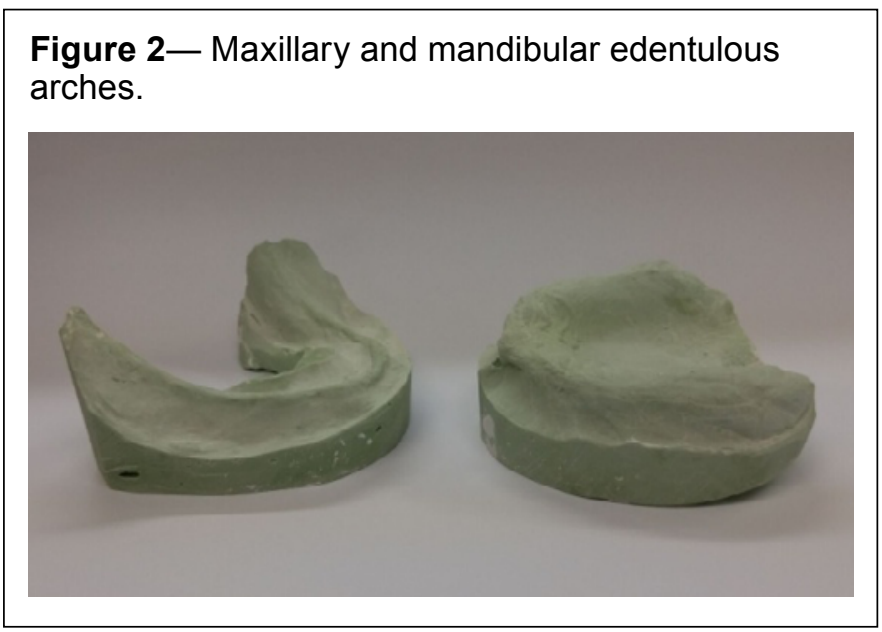

Figure 3-Maxillary and mandibular full denture appliances with the oral appliance hardware set in place and with posterior stops present.

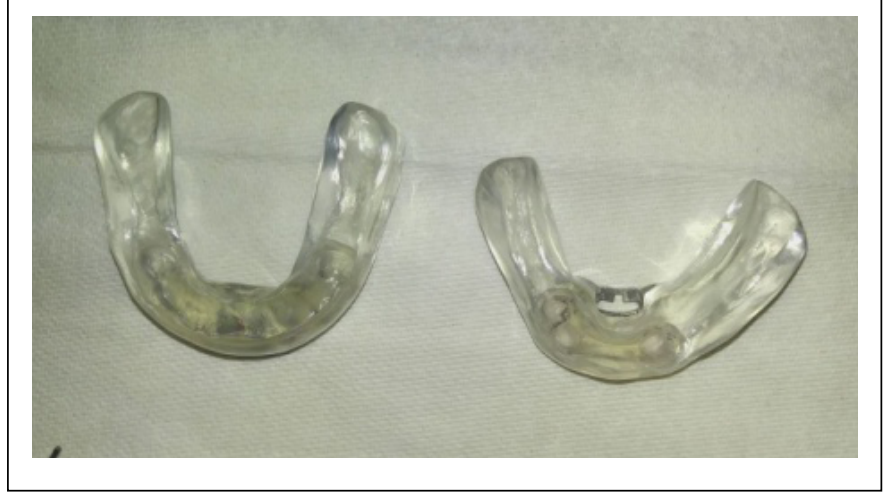

contacts rather than the single anterior stop while maintaining a balanced occlusion in all excursions. The patient was allowed to sit for $30 \mathrm{~min}$ to check for sore spots and verify comfort. Three months after insertion, the appliances have maintained excellent retention and stability and only one sore spot occurred that required adjustment. At the end of the titration period, the patient was referred back to her physician of record for a follow-up in-laboratory dynamic titration. With dynamic titration, the patient's initial titrated jaw position is determined using high-resolution pulse oximetry (HRPO), and during the sleep study the sleep technician moves the mandible $0.5 \mathrm{~mm}$ forward after each rapid eye movement cycle, depending on the patient's comfort and PSG results. A follow-up PSG showed an AHI of 2.5 events/h and nadir of $89 \%$ at $0.75 \mathrm{~mm}$ past her starting point (cuspid to cuspid end on position). Of interest was the fact that at $0.5 \mathrm{~mm}$ past this cuspid end on starting position her AHI was 31.8 events/h and nadir was $77 \%$. The patient's final Epworth Sleepiness Scale score was 1 and her FSS was 13 . We have placed the patient into our recall system.

\section{CASE \#2}

This 62-y-old male patient with a diagnosis of severe OSA was seen in July 2016. He was prescribed an oral appliance and referred by his sleep physician of record. His PSG showed an AHI of 33.8 events/h, respiratory disturbance index of 33.8 events/h, and nadir of $86 \%$. The patient was on unpaid medical leave until his OSA was under control. He was being treated for gastrointestinal reflux disease, high blood pressure, ischemic heart disease; he has a cardiac pacemaker, chronic fatigue, hypersomnolence, mood disorder, depression, and intestinal issues. His current medications are Aspirin, Atorvastatin, Carvedilol, Clopidogrel, Fenofibrate, Fluoxetine, Fosinopril Sodium, Omepreazole, and magnesium. The patient is totally edentulous with a minimal lower ridge, and his existing dentures are $20 \mathrm{y}$ old.

Our treatment plan was to make an upper and lower appliance with the metal hardware transferred to denture material. Because of the severity of the patient's apnea, we would also be using combination therapy with the TAP-PAP Chairside Interface (Airway Management, Carrollton, TX) attached to a loaner autotitrating CPAP unit provided by my office. The patient was instructed not to wear his dentures from the time he went to bed until his appointment. A two-part, chemically compatible, irreversible hydrocolloid impression material was used to take the master impressions. An upper and lower custom tray with wax rims was made to establish the proper vertical and bite positions. The key to this technique is to register the bite without freeway space. Several measurements were taken at the patient's existing rest vertical dimension by measuring the distance from a mark made on his upper and lower vermillion border. The wax rims were modified so that this vertical dimension is replicated and the bite was taken at an estimated end-on position. The impressions and bite were sent to the laboratory and the injection system was used.

Only minor adjustments were needed when the appliance was seated. At this appointment, posterior stops were placed bilaterally at the most posterior location on the lower appliance to create a three-point balanced occlusion in all excursions. Without the freeway space and with the posterior stops placed, the appliance has mild positive pressure on both units holding it in place while being worn. The TAP-PAP Chairside Interface was also placed during this appointment and attached to an autotitrating CPAP unit with a heated hose. The 
physician-prescribed pressures were set chairside at 8 to 20 $\mathrm{cmH}_{2} \mathrm{O}$. The patient comfortably wore the just-seated assembly for $30 \mathrm{~min}$ before being released.

The office protocol is to have the PAP chip download taken after 1 night of usage and forwarded to the patient's physician of record. In this case, the first night download showed a reduction of the AHI from 33.8 events/h to 3.6 events/h, with an average pressure of $9.8 \mathrm{~cm} \mathrm{H}_{2} \mathrm{O}$ and usage of $8 \mathrm{~h} 22$ $\mathrm{min}$, and $1 \mathrm{~min}$ of large leak time. At no time during the night was the denture dislodged, and the patient slept comfortably with it all night. At approximately $2 \mathrm{w}$ HRPO was performed. The results showed a time above $90 \%$ oxygen (T90) at $99.2 \%$, mean saturation of peripheral oxygen of $94.5 \%$, nadir of $86 \%$, and normal pulse rate but with elevated desaturation indices at $2 \%, 3 \%$, and $4 \%$. Performing HRPO with combination therapy is important because a substantial number of patients will have a normal AHI on their PAP download, yet T90 will be abnormal. If an abnormal T90 is found, then the patient is referred back to the physician of record with a recommendation for a pulmonary referral. Ancillary oxygen through the PAP unit has been the treatment of choice for my previous patients. Six weeks after therapy was started, the final PAP download for this patient showed an AHI of 2 events/h with a median pressure of $9.4 \mathrm{~cm} \mathrm{H}_{2} \mathrm{O}$ and average daily usage of $6 \mathrm{~h}$ $21 \mathrm{~min}$. The patient's physician of record decided to utilize the HRPO and PAP download information instead of having the patient undergo another sleep study. The patient has now been able to return to work.
Utilizing this technique will allow for more treatment flexibility for the clinician, patient comfort, longer appliance life span, appliance modification, and a substantial reduction of a patient's financial obligation since the need for and expense of dental implants can possibly be averted.

\section{REFERENCES}

1. Johns MW. A new method for measuring daytime sleepiness: the Epworth sleepiness scale. Sleep. 1991;14(6):540-545.

2. Valko PO, Bassetti CL, Bloch KE, Held U, Baumann CR. Validation of the fatigue severity scale in a Swiss cohort. Sleep. 2008;31(11):1601-1607.

\section{SUBMISSION \& CORRESPONDENCE INFORMATION}

Submitted for publication November, 2016

Submitted in final revised form November, 2016

Accepted for publication November, 2016

Address correspondence to: Martin A. Denbar, DDS, Diplomate,

ABDSM, Austin Sleep Apnea and Snoring Therapy, $7800 \mathrm{~N}$.

Mopac \#300, Austin, TX 78759; Tel: (512) 338-8120; Email:

dr.denbar@austinapnea.com

\section{DISCLOSURE STATEMENT}

This was not an industry-supported study. Dr. Denbar's private practice in Austin, Texas is totally devoted to Dental Sleep Medicine. Dr. Denbar also serves as an Adjunct Assistant Professor at Texas A\&M School of Medicine and is the founder of High-Performance Breathing Technology. No conflicts of interest are known. There was no investigational or off-label use. The work was performed in his private practice. 



\title{
Airway Evaluation in Response to Hypoglossal Nerve Stimulation: A Case Report
}

Tarek Elshebiny, BDS, MSD ${ }^{1,2}$; Divya Venkat, MD³ Madeleine Strohl, MD4; Kingman Strohl, MD³; Diana Ponsky, MD; Juan Martin Palomo, DDS, MSD ${ }^{5}$

${ }^{1}$ Case Western Reserve University, Cleveland, $\mathrm{OH} ;{ }^{2}$ Department of Orthodontics, College of Dentistry, Future University of Egypt, Cairo, Egypt; ${ }^{3}$ Case Western Reserve University School of Medicine, Cleveland, $\mathrm{OH} ;{ }^{4}$ Department of Otolaryngology, University of California San Francisco, San Francisco, CA; ${ }^{5}$ Department of Orthodontics and Craniofacial Imaging Center, School of Dental Medicine, Case Western Reserve University, Cleveland, $\mathrm{OH}$

\begin{abstract}
STUdy OвJECTIVEs: Upper airway stimulation (UAS) using a unilateral implantable neurostimulator for the hypoglossal nerve is a relatively novel option for patients with obstructive sleep apnea (OSA). This may be especially useful to patients who cannot tolerate continuous positive airway pressure (CPAP) or oral appliance therapy. The aim of this study is to describe the use of relatively new technology in treatment of OSA using a fully implanted system by stimulating the hypoglossal nerve, and to evaluate pharyngeal changes in a patient with an implanted UAS system.

METHODS: A 61-y-old man with a diagnosis of severe OSA, apnea-hypopnea index (AHI) of 37 events/h, lowest oxygen saturation of $85 \%$, and claustrophobia who could not tolerate CPAP therapy underwent the following procedures at different times, two uvulopalatopharyngoplasties, two nasal septum procedures, maxillary-mandibular advancement, genioglossus advancement surgeries, and insertion of oral appliances, decreasing the AHI to 28 events/h (moderate). A more permanent solution was desired. The UAS system was implanted, and soon afterward, three lateral cephalograms were taken at different degrees of stimulation: no stimulation (T1), low voltage (T2), and high voltage (T3).

RESULTS: UAS led to a decrease in the AHI to 8.5 (mild), with an acceptable oxygen saturation of $90 \%$, with the patient reporting significant improvement in quality of life. With stimulation, the upper pharyngeal width increased from $6.5 \mathrm{~mm}$ (T1) to $7.1 \mathrm{~mm}$ (T2) and $8.3 \mathrm{~mm}$ (T3). The lower pharyngeal width increased from $5.5 \mathrm{~mm}$ (T1) to $8.5 \mathrm{~mm}$ (T2), and $9.5 \mathrm{~mm}$ (T3).

ConcLusion: Implantable UAS may be considered in patients with OSA who have difficulties with CPAP therapy.

KEYWORDS: hypoglossal nerve, OSA, sleep apnea, upper airway stimulation

Citation: Elshebiny T, Venkat D, Strohl M, Strohl K, Ponsky D, Palomo JM. Airway evaluation in response to hypoglossal nerve stimulation: a case report. Journal of Dental Sleep Medicine. 2017;4(1):15-17.
\end{abstract}

\section{INTRODUCTION}

Obstructive sleep apnea (OSA) is a common disorder characterized by repetitive collapse of the upper airway during sleep, resulting in recurrent arousals. ${ }^{1}$ According to the American Sleep Association, OSA affects more than 12 million Americans, and when left untreated, it has been linked to high blood pressure, heart attack, stroke, and depression. ${ }^{2}$ Continuous positive airway pressure (CPAP) is the standard of care for treating OSA. Despite the uniform success of CPAP therapy, patient compliance remains a problem. Compliance rates have been reported as low as 54\%, making a successful long-term treatment difficult to achieve. ${ }^{2}$

A relatively novel treatment in OSA for patients unable to use CPAP therapy is upper airway stimulation (UAS) therapy using a fully implanted system. The Inspire UAS system (Inspire Medical Systems, Inc, Maple Grove, MN) is an FDA-approved system offered for the treatment of moderate to severe OSA. This procedure has been shown to decrease the severity and symptoms of OSA in select patients. ${ }^{3}$

\section{REPORT OF CASE}

This is the report of a case of a 61-y-old man with a diagnosis of severe OSA, an apnea-hypopnea index (AHI) of 37 events/h, and lowest oxygen saturation of $85 \%$ who was unhappy with the management of his OSA. He was claustrophobic, unable to tolerate CPAP and had poor compliance with oral appliances. Previous treatment attempts included two uvulopalatopharyngoplasties, two septoplasties, one inferior turbinate reduction, separate genioglossus advancement procedures, and maxillary-mandibular advancement surgery. The patient used several different oral appliances and a Winx machine (Apnicure Inc., Redwood City, CA). After this series of procedures, a polysomnogram showed that the patient's AHI was decreased to 28 events/h. Because the results still were not satisfactory, the Inspire UAS system was suggested, and it wassoon implanted to manage the still-existing clinically significant OSA. The patient was part of a clinical trial, with Institutional Review Board approval. Images obtained were part of the study and approved by two hospitals and one institution in the 
Figure 1-Lateral cephalometric radiograph.
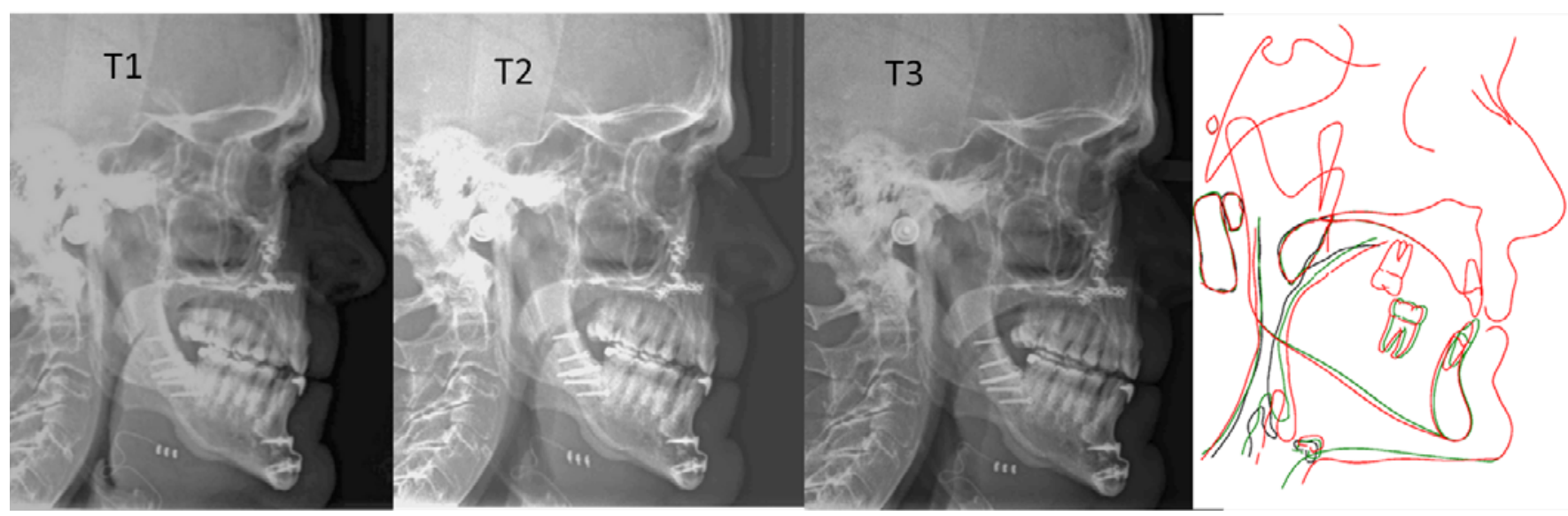

Lateral cephalometric radiograph with implanted system, but showing no activation of the upper airway (T1), low stimulation voltage (T2), high stimulation voltage (T3) and cephalometric superimposition on the cranial base including T1 (black), T2 (green), and with higher voltage T3 (red).

Table 1-The landmarks and reference lines of the upper airway.

\begin{tabular}{|c|c|c|}
\hline Measurement & Landmarks & Definition \\
\hline Nasopharynx length & PNS-PPW1 (mm) & $\begin{array}{l}\text { Measured as the distance from posterior nasal spine (PNS) to posterior pharyngeal } \\
\text { wall (PPW1). }\end{array}$ \\
\hline Retropalatal length & PSP-PPW2 (mm) & $\begin{array}{l}\text { Measured as the distance between the most posterior point of the soft palate (PSP) } \\
\text { and the posterior pharyngeal wall (PPW2). }\end{array}$ \\
\hline Oropharynx length & PTO-PPW3 (mm) & $\begin{array}{l}\text { Measured as the distance from the mandibular inferior border in the posterior area } \\
\text { of the tongue (PTO) to the posterior pharyngeal wall (PPW3), which can be defined } \\
\text { as retrolingual region. }\end{array}$ \\
\hline Hypopharynx length & V-PPW4 (mm) & $\begin{array}{l}\text { Measured as the distance between the base of the epiglottic vallecular (V) and the } \\
\text { posterior pharyngeal wall (PPW4). }\end{array}$ \\
\hline Soft palate length & PNS-U (mm) & Measured from PNS to the uvula (U). \\
\hline Hyoid bone horizontal position & H-PPW5 (mm) & $\begin{array}{l}\text { Measured as the distance between the most anterosuperior point of hyoid bone }(\mathrm{H}) \text { and } \\
\text { PPW5. }\end{array}$ \\
\hline Hyoid bone vertical position & $\mathrm{H}-\mathrm{MP}(\mathrm{mm})$ & $\begin{array}{l}\text { Measured from the most anterosuperior point of hyoid bone }(\mathrm{H}) \text { to the mandibular } \\
\text { plane (MP). }\end{array}$ \\
\hline
\end{tabular}

United States. Three lateral cephalograms were taken using the Carestream CS9300 (Carestream Health, Inc., Rochester, NY) at $82 \mathrm{kVp}, 12 \mathrm{~mA}, 0.8 \mathrm{sec}$, to evaluate the pharyngeal airway changes and the movement of the hyoid bone. The first cephalogram was taken without hypoglossal nerve stimulation (T1), the second one with a stimulation of 1.4 volts (T2), and a third one with a stimulation of 1.7 volts (T3) (Figure 1, Table 1). The measurement of the pharyngeal airway space was performed using seven linear variables. 4

\section{RESULTS}

Clinically significant changes were seen between $\mathrm{T} 1, \mathrm{~T} 2$, and T3 at the oropharynx, hypopharynx, and hyoid bone position. A slight change was also found in the retropalatal length, but no changes were found for nasopharynx and soft palate lengths. The oropharynx length changed from $5.5 \mathrm{~mm}$ at $\mathrm{T} 1$, to $8.5 \mathrm{~mm}$ at T2, and to $9.5 \mathrm{~mm}$ at T3. The hypopharynx length showed an even larger change with 14.5 at $\mathrm{T} 1,17.5$ at $\mathrm{T} 2$, and 21.5 at T3. The hyoid bone moved significantly both vertically and horizontally, with the horizontal position starting at 33 $\mathrm{mm}$ (T1), going to $34.5 \mathrm{~mm}$ at T2, and finishing at $36 \mathrm{~mm}$ (T3). Vertically the change was upward, moving closer to the mandible, registered as $32 \mathrm{~mm}$ at $\mathrm{T} 1,30.5 \mathrm{~mm}$ at $\mathrm{T} 2$, and 29 $\mathrm{mm}$ at $\mathrm{T} 3$. The retropalatal length increased from $6.5 \mathrm{~mm}(\mathrm{~T} 1)$ to $7.1 \mathrm{~mm}$ (T2), and then to $8.3 \mathrm{~mm}$ with the higher stimulation (T3). No changes whatsoever were noticed in the nasopharynx or the soft palate length. Overall superimposition of T1, T2, and T3 (Figure 1) showed the effect on upper airway opening at different levels during hypoglossal nerve stimulation. A sleep study was conducted 5 mo after the UAS was in use, showed the AHI decreased from 28 to 8.5 events/h and acceptable oxygen saturation of $90 \%$ was achieved using 1.4 volts. In $1 \mathrm{y}$ the patient reported significant improvement in quality of life.

\section{DISCUSSION}

This is a report of a relatively new option for patients with OSA who are not able to achieve stability with CPAP or more 
traditional options. It is important to include the airway morphology into the orthodontic treatment plan. As healthcare providers, we would be serving our patients better if we could help identifying symptoms and possible options for our patients. Cephalometric analyses may also be useful in identifying potential markers. In the current case report, cephalometric radiographs helped us to evaluate the pharyngeal airway changes. The findings suggest that unilateral stimulation of the hypoglossal nerve, using an implantable UAS system, increases airway area at multiple levels. The position of the hyoid bone could be of significant importance to the craniofacial practitioner, as the hyoid bone is easily identified on lateral cephalograms. ${ }^{5}$

\section{CONCLUSIONS}

An implantable UAS may be considered for patients with OSA who have difficulties with CPAP therapy.

\section{REFERENCES}

1. Malhotra A, White DP. Obstructive sleep apnea. Lancet. 2002;360(9328):237-245.

2. Always Tired? You May Have Sleep Apnea. U.S. Food \& Drug Adminstration Web site. http://www.fda.gov/forconsumers/ consumerupdates/ucm330932.htm. Updated April 11, 2016. Accessed May 2, 2016.
3. Veasey SC, Guilleminault C, Strohl KP, et al. Medical therapy for obstructive sleep apnea: a review by the medical therapy for obstructive sleep apnea task force of the standards of practice committee of the American Academy of Sleep Medicine. Sleep. 2006;29(8):1036-1044.

4. Schwartz AR, Bennett ML, Smith PL, et al. Therapeutic electrical stimulation of the hypoglossal nerve in obstructive sleep apnea. Arch Otolaryngol Head Neck Surg. 2001;127(10):1216-1223.

5. Lowe A, Ono T, Ferguson KA, Pae EK, Ryan CF, Fleetham JA. Cephalometric comparisons of craniofacial and upper airway structure by skeletal subtype and gender in patients with obstructive sleep apnea. Am J Orthod Dentofacial Orthop. 1996;110(6):653-664.

6. Phoenix A, Valiathan M, Nelson S, Strohl KP, Hans M. Changes in hyoid bone position following rapid maxillary expansion in adolescents. Angle Orthod. 2011;81(4):632-638.

\section{SUBMISSION \& CORRESPONDENCE INFORMATION}

Submitted for publication August, 2016 Submitted in final revised form November, 2016

Accepted for publication November, 2016

Address correspondence to: Tarek Elshebiny, BDS, MSD, 2124 Cornell

Rd. Cleveland, OH 44106; Tel: (216) 466-4641; Email: tme18@case.edu

\section{DISCLOSURE STATEMENT}

Dr. Strohl reports grants from Inspire, outside the submitted work. Work was done at University Hospitals and Case Western Reserve University School of Dental Medicine. 



\title{
Case Report: Retention of a Thermoplastic-Lined Dental Sleep Appliance
}

\author{
Rachel M. Uppgaard, DDS \\ Minneapolis Veterans Affairs Medical Center
}

\begin{abstract}
A thermoplastic appliance (Dynaflex dorsal appliance) was fabricated for a patient who became overzealous when heating the appliance to seat it intraorally. The appliance could not be removed manually. The appliance required removal with a high-speed handpiece and aggressive sectioning of the acrylic and underlying thermoplastic lining. Patients should be strongly advised to avoid overheating these appliances prior to intraoral placement.
\end{abstract}

KEYWORDS: Dynaflex, maxillary sleep appliance, retained sleep appliance, thermoplastic-lined sleep appliance

Citation: Uppgaard RM. Case report: retention of a thermoplastic-lined dental sleep appliance. Journal of Dental Sleep Medicine. 2017;4(1):19-20.

\section{INTRODUCTION}

In patients with obstructive sleep apnea (OSA), dental sleep appliances can provide an excellent noninvasive method of treating this condition. ${ }^{1}$ These appliances are effective and in general have a low side effect profile. There are no reports in the literature of dental appliances being retained and requiring aggressive removal.

\section{REPORT OF CASE}

A 68-y-old man was referred to the dental sleep clinic for evaluation of OSA and fabrication of a dental sleep appliance. He had a respiratory disturbance index of 32.8 events/h, Epworth Sleepiness Scale score of 14, and a $7.7 \mathrm{~mm}$ posterior airway space as measured on lateral cephalogram at the narrowest point. The patient has a history of type 2 diabetes mellitus, atrial fibrillation on chronic anticoagulation, hypertension, and defibrillator. A maxillary Dynaflex dorsal sleep appliance (DynaFlex, St. Ann, MO) was fabricated and was given to the patient with the following instructions:

(1) Seat sleep appliances with hands/do NOT bite into place.

(2) Place under warm water before seating.

(3) Use AM Aligner (Tap AM Aligner, Patterson Dental Laboratories, Eagan, MN) for 10-15 min.

The patient followed directions and placed the appliance in warm water for 10 to $15 \mathrm{~min}$, but the appliance still did not fit; he placed it under hot water for a longer period and thereafter it fit well. He experienced the best night of sleep in years. In the morning, the patient could not remove the appliance. He presented to the emergency department $6 \mathrm{~h}$ after being unable to remove the appliance; the emergency department staff also were unable to remove the appliance. The patient was evaluated by the oral and maxillofacial surgery service. It was noted that the appliance was very stable intraorally and that the patient had ecchymosis in the bilateral maxillary labial vestibules consistent with anticoagulation and multiple attempts at appliance removal. The appliance was locked into the undercuts of the patient's teeth.

The providers anesthetized the patient and heated the thermoplastic lining via lavage with very warm, sterile water for $10 \mathrm{~min}$; however, there was no substantial increase in ability to mobilize the appliance. This further indicated that the appliance was locked into the interproximal spaces. At this time, a high-speed dental handpiece was used to cut the appliance into five pieces (one cut on the distal aspect of the central incisors bilaterally, one cut in the premolar region bilaterally) on the buccal aspect of the appliance (Figure 1). Unfortunately, even though these pieces had more mobility, because of the Dynaflex material being hardened between each tooth, this required removal of the buccal acrylic around each tooth as well as the lining material between each tooth. Next, the lining was again heated with warm, sterile water and the palatal aspect of the appliance was removed from the teeth. The maxillary arch was irrigated, and the dentition was flossed to remove any remaining material. The total procedure time was $1 \mathrm{~h}$.

The patient was prescribed chlorhexidine to manage gingival trauma, and acetaminophen as needed. He recovered well and had a new sleep appliance fabricated that did not have a thermoplastic lining.

\section{DISCUSSION}

This case brings up an interesting point of discussion that is now being addressed with all of the patients at our institution. So often patients see the appliances heated in hot water, and when they receive instructions to use warm water to heat their appliance before seating, they may become overly zealous in their attempts to seat these appliances.

The providers attempted removal via only a few pieces, but quickly realized that the acrylic and thermoplastic material required drilling between each tooth to remove as much of the undercut material as possible. The Dynaflex is quite adherent to the acrylic. 
Figure 1-Dynaflex appliance following removal.

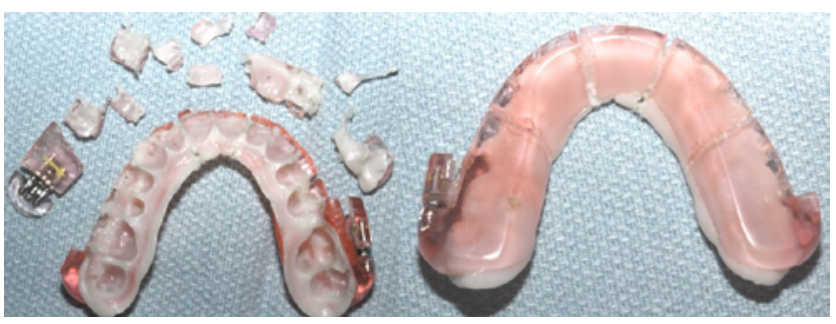

Note the cuts in the acrylic, as well as the multiple pieces removed from the buccal aspect.

We would encourage providers to use caution in treatment planning: patients with large embrasures and undercuts in the interproximal spaces may benefit from appliances that do not have a thermoplastic lining.

We would encourage providers to instruct patients to use caution while heating appliances that have a thermoplastic lining, and if retention occurs, to plan for extensive drilling to remove the appliance without damaging the teeth.
A review of the literature did not identify any other cases where a sleep appliance was retained and unable to be removed with manual manipulation.

\section{REFERENCES}

1. Ramar K, Dort LC, Katz SG, et al. Clinical practice guideline for the treatment of obstructive sleep apnea and snoring with oral appliance therapy: an update for 2015. Journal of Dental Sleep Medicine. 2015;2(3):71-125.

\section{SUBMISSION \& CORRESPONDENCE INFORMATION}

Submitted for publication November, 2016

Submitted in final revised form November, 2016

Accepted for publication November, 2016

Address correspondence to: Rachel M. Uppgaard, DDS, 2U Dental, One

Veterans Drive, Minneapolis, MN 55417; Tel: (612) 209-9176; Fax: (612)

727-5669; Email: uppg0003@umn.edu

\section{DISCLOSURE STATEMENT}

No financial support was received for this case report. There are no conflicts of interest. No off-label use of products is discussed. 


\section{Monobloc or Adjustable MAD?}

\author{
Hendrik J. Remmelink, DDS, PhD
}

Private Practice of Orthodontics, Almelo, the Netherlands

I want to comment on the editorial entitled "When Is a Monobloc not a Monobloc? Cautions for Clinical Practice" published by Dr. Dort in the October 2016 issue of the Journal of Dental Sleep Medicine. ${ }^{1}$ The author states that the practice of cutting apart and repositioning monobloc adjustable mandibular advancement devices (MADs) would be prohibitive in terms of clinician time and laboratory expense. According to Dr. Dort, the cost of a clinical process using monobloc MADs is likely to be more than that if an adjustable device is used. However, I think that some other factors also should be taken into account.

Usually in health economics, the principle of a cost-effectiveness analysis is to compare total costs and treatment effectiveness of various treatments over the long term. Based on such a comparison, it can be determined whether differences in cost are acceptable. When comparing the cost of monobloc with that of adjustable devices, not only the cost of titration but also differences in prices between MADs should be considered. These costs depend on the type of appliance, dental laboratory cost, and country of manufacture, but in general the cost of an adjustable device is much higher than that of a monobloc MAD. In the Netherlands, for example, the laboratory cost for patented, adjustable appliances is approximately fivefold the price of custom monobloc MADs. According to a study in an American publication, ${ }^{2}$ the total fee for MADs with dental consultation, follow-up visits, radiographs, and the price of the appliance itself reportedly is in the range of $\$ 2,500$ to $\$ 3,000$. In addition, the frequency and cost of repositioning, repairs, and replacements of these devices should be compared.

Furthermore, health care decision-making about the effectiveness of treatments preferably should be based on large well-controlled, long-term, prospective randomized clinical trials. However, to my knowledge there are only two studies comparing the effectiveness of monobloc and adjustable MADs. The first study is a short-term investigation with a follow-up of $1 \mathrm{mo}$ and a small sample size of only 24 patients with OSA. ${ }^{3}$ On the basis of this investigation it is suggested that adjustable MADs are more effective than monobloc appliances. One of the flaws of the study is that the mean total amount of mandibular advancement of the adjustable MADs was $85 \%$ of maximum compared to $75 \%$ in the monobloc group. It should be noted that in the literature a greater amount of mandibular advancement has been reported to be associated with greater improvement of OSA. ${ }^{4}$ The second study also suggests that adjustable MADs are more effective than monobloc MADs. ${ }^{5}$ However, this study was retrospective, also short-term, and had no standardized duration of followup. No information was provided about possible differences in the amount of mandibular advancement between the two types of appliances.

It is obvious that over the past years many commercially available adjustable MADs have been promoted in journals and at congresses and courses. Nevertheless, I think that based on current research evidence it is difficult to draw conclusions regarding differences in total cost and effectiveness between treatments with monobloc and adjustable appliances, especially over the long term. In addition, the adverse effects of these appliances and treatment compliance need to be investigated. In my opinion, primarily high-quality prospective randomized trials are required to analyze the cost-effectiveness of both types of MADs before including recommendations regarding these appliances in clinical guidelines.

\section{CITATION}

Remmelink HJ. Monobloc or adjustable MAD? Journal of Dental Sleep Medicine. 2017;4(1):21.

\section{REFERENCES}

1. Dort LC. When is a monobloc not a monobloc? Cautions for clinical practice. Journal of Dental Sleep Medicine. 2016;3(4):109.

2. Abad VC, Guilleminault C. Treatment options for obstructive sleep apnea. Curr Treat Options. Neurol. 2009;11(5):358-367.

3. Sari E, Menillo S. Comparison of titratable oral appliance and mandibular advancement splint in the treatment of patients with obstructive sleep apnea. ISRN Dent. 2011;2011:581692.

4. Aarab G, Lobbezoo F, Hamburger HL, Naeije M. Effects of an oral appliance with different mandibular protrusion positions at a constant vertical dimension on obstructive sleep apnea. Clin Oral Investig. 2010;14(3):339-345.

5. Lettieri CJ, Paolino N, Eliasson AH, Shah AA, Holley AB. Comparison of adjustable and fixed oral appliances for the treatment of obstructive sleep apnea. J Clin Sleep Med. 2011;7(5):439-445.

\section{SUBMISSION \& CORRESPONDENCE INFORMATION}

Submitted for publication November, 2016

Accepted for publication November, 2016

Address correspondence to: Hendrik J. Remmelink, DDS, PhD, Private

Practice of Orthodontics, Wierdensestraat 36, 7607 GJ Almelo, The

Netherlands; Email: remmelinkh@gmail.com

\section{DISCLOSURE STATEMENT}

Dr. Remmelink has indicated no financial conflicts of interest. 
